\title{
Radiation Response of Synthetic U-containing Sn-Zr Based Pyrochlore
}

\author{
Jiaming Zhang*, Qiaona Hu*, T. S. Livshits**, S. V. Yudintsev**, Jie Lian***, R. C. Ewing*
}

* Departments of Geological Sciences and Materials Science \& Engineering, University of Michigan, Ann Arbor, Michigan 48109-1005, USA

** Institute of Geology of Ore Deposits, Petrography, Mineralogy, and Geochemistry, Russian Academy of Sciences, Moscow, 119017 Russia

*** Department of Mechanical, Aerospace \& Nuclear Engineering, Rensselaer Polytechnic Institute, Troy, NY 12180, USA

A closed nuclear fuel cycles will generate plutonium and minor actinides ( $\mathrm{Np}, \mathrm{Am}, \mathrm{Cm})$ that are required to be immobilized into durable nuclear waste forms for long-term geologic disposal. Isometric pyrochlore, $\mathrm{A}_{2} \mathrm{~B}_{2} \mathrm{O}_{7}$, is a promising host phase for the incorporation of actinides. Many studies have simulated the alpha-decay damage in a wide range of compositions using ion beam irradiation. In the present study, the response to the radiation damage of U-doped Sn-Zr based pyrochlore has been studied by $1-\mathrm{MeV} \mathrm{Kr}^{+}$ion irradiation and characterized by in situ transmission electron microscopy (TEM).

Sn-Zr based, lanthanides-mixed pyrochlore doped with $U$ was synthesized by mechanical activation with two-stages sintering of the oxide mixture for $5 \mathrm{hrs}$ at $1350 \mathrm{C}$. The detailed sample compositions was listed in Table 1, with the general formula $(\mathrm{REE})_{2}(\mathrm{Sn}-\mathrm{Zr}, \mathrm{U})_{2} \mathrm{O}_{7}$. The mixed composition of $\mathrm{RE}$ oxides corresponds to formula as $\mathrm{REE}_{2}=\mathrm{La}_{0.26} \mathrm{Ce}_{0.51} \mathrm{Pr}_{0.24} \mathrm{Nd}_{0.79} \mathrm{Sm}_{0.14} \mathrm{Eu}_{0.04} \mathrm{Gd}_{0.03}$. A SEM image of the Sn-Zr sample was shown in Fig. 1a as a representative of the microstructure of pyrochlore with a small amount of impurity. The ordered crystal structure and composition were characterized using a JEOL JEM 2010F electron microscope. (EDS was shown in Fig. 1b) A 1-MeV $\mathrm{Kr}^{2+}$ ion irradiation was performed in the IVEM-Tandem Facility at the Argonne National Laboratory over the temperature range from 50 to $700 \mathrm{~K}$. The microstructure evolution was monitored intermittently by taking selected area electron diffraction (SAED) pattern during irradiation.

A series of SAED patterns of Sn-pyrochlore and Zr-pyrochlore irradiated by 1-MeV $\mathrm{Kr}^{2+}$ ions at different ion fluencies at room temperature (RT) and $50 \mathrm{~K}$ respectively was shown in Fig 2. $(\mathrm{REE})_{2}\left(\mathrm{Sn}_{1.93} \mathrm{U}_{0.07}\right) \mathrm{O}_{7}$ pyrochlore was susceptible to radiation-induced amorphization at $\mathrm{RT}$ after a fluence of $6 \times 10^{14}$ ions $/ \mathrm{cm}^{2}$, while $(\mathrm{REE})_{2}\left(\mathrm{Zr}_{1.93} \mathrm{U}_{0.07}\right) \mathrm{O}_{7}$ was radiation resistant without amorphization even at $50 \mathrm{~K}$ after a fluence of $2.5 \times 10^{15}$ ions $/ \mathrm{cm}^{2}$, instead forms a disordered fluorite structure. The critical amorphization was plotted as a function of temperature as shown in Fig. 3. The critical temperature of Sn-pyrochlore, above which the complete amorphization does not occur, is $650 \mathrm{~K}$. The mixed $\mathrm{Zr}$-Sn based pyrochlore shows an intermediated response with a critical temperature of 510K.(summarized in Table 1) The relation of radiation resistance and cation ionic radius ratio shows that the material with greater resistance to irradiation-induced amorphization has structure closer to the fluorite structure (with smaller $r_{A} / r_{B}$ ).

This work was supported as part of the Materials Science of Actinides, an Energy Frontier Research Center funded by the U.S. Department of Energy, Office of Science, Office of Basic Energy Sciences under Award Number DE-SC0001089. 
Table 1. Summary of the characteristics of synthesized U-doped pyrochlore samples and their irradiation response data. $\left(\mathrm{A}_{2}: \mathrm{La}_{0.26} \mathrm{Ce}_{0.51} \mathrm{Pr}_{0.24} \mathrm{Nd}_{0.79} \mathrm{Sm}_{0.14} \mathrm{Eu}_{0.04} \mathrm{Gd}_{0.03}\right)$.

\begin{tabular}{|c|c|c|c|c|}
\hline sample & stoichiometry & $\boldsymbol{r}_{A} / \boldsymbol{r}_{\boldsymbol{B}}$ & $\mathbf{F}_{\mathbf{c}}$ at RT (ions/cm $\left.{ }^{2}\right)$ & $\mathbf{T}_{\mathbf{c}}$ \\
\hline $\mathrm{Zr}$ & $\mathrm{A}_{2}\left(\mathrm{U}_{0.07} \mathrm{Zr}_{1.93}\right) \mathrm{O}_{7}$ & 1.544 & $2.5 \times 10^{15}$ & $<50 \mathrm{~K}$ \\
\hline $\mathrm{Sn}-\mathrm{Zr}$ & $\mathrm{A}_{2}\left(\mathrm{U}_{0.07} \mathrm{Zr}_{0.93} \mathrm{Sn}\right) \mathrm{O}_{7}$ & 1.587 & $1.3 \times 10^{15}$ & $510 \mathrm{~K}$ \\
\hline $\mathrm{Sn}$ & $\mathrm{A}_{2}\left(\mathrm{U}_{0.07} \mathrm{Sn}_{1.93}\right) \mathrm{O}_{7}$ & 1.630 & $0.75 \times 10^{15}$ & $650 \mathrm{~K}$ \\
\hline
\end{tabular}

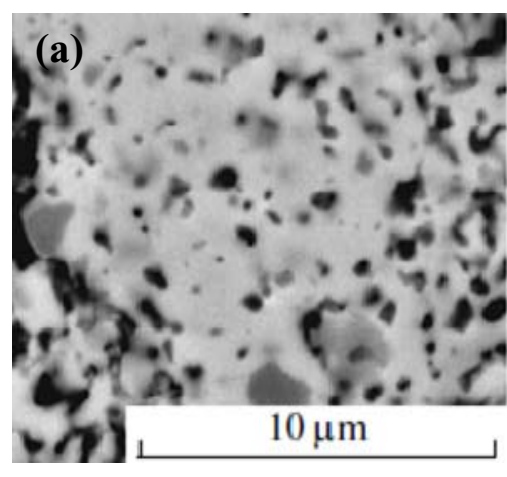

(b)

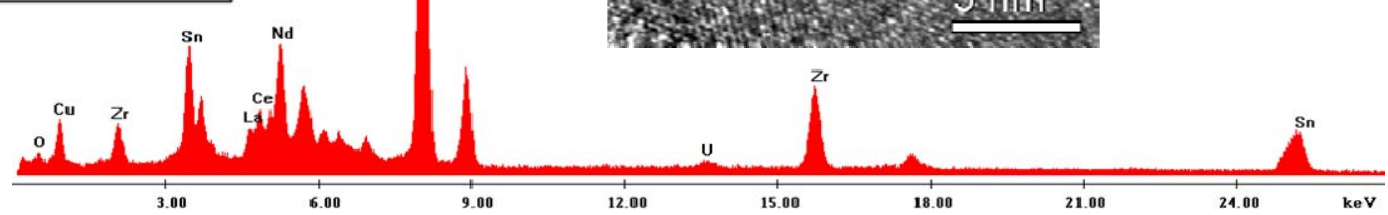

Fig. 1 (a) SEM image of microstructure of $(\mathrm{REE})_{2}\left(\mathrm{U}_{0.07} \mathrm{Zr}_{0.93} \mathrm{Sn}\right) \mathrm{O}_{7}$ pyrochlore and corresponding energy-dispersive X-ray spectrum (b) and HRTEM image (c).
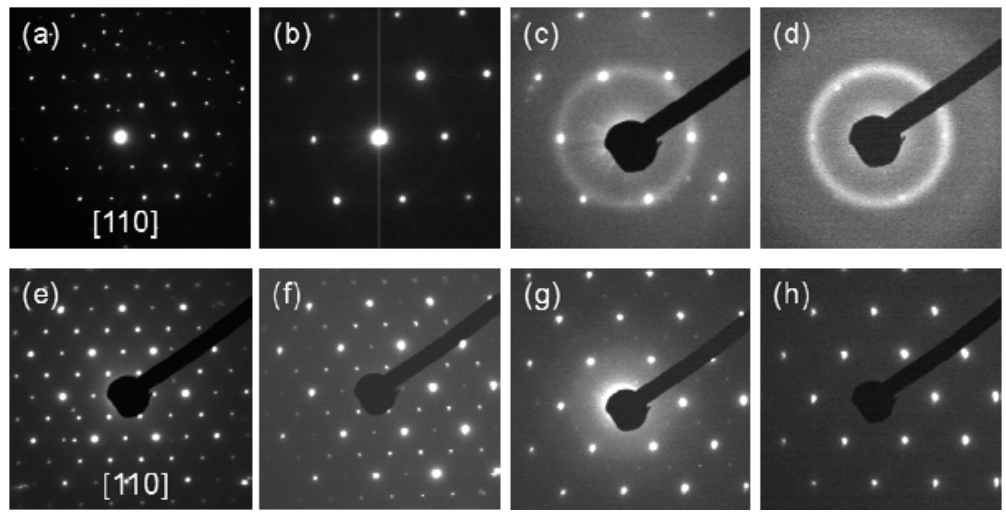

Fig. 2 A series of SAED patterns for Sn-pyrochlore irradiated by $1-\mathrm{MeV} \mathrm{Kr}^{2+}$ ions at different ion fluencies of (a)original, (b) $2.5 \times 10^{14}$, (c) $4 \times 10^{14}$ and (d) $6 \times 10^{14}$ ions $/ \mathrm{cm}^{2}$ at RT, and for $\mathrm{Zr}$-pyrochlore irradiated at $50 \mathrm{~K}$ :
(e)original,
(g) $4 \times 10^{14}$,
(h) $1.25 \times 10^{15}$ ions $/ \mathrm{cm}^{2}$.

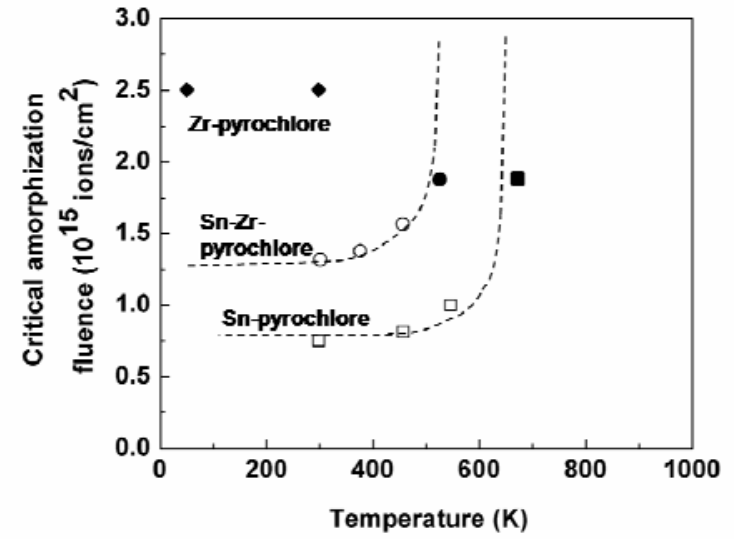

Fig. 3 The amorphization fluences of U-doped pyrochlore as a function of temperature. 